\title{
A EDUCAÇÃo BÁSICA NA VENEZUELA PÓS-CHAVÉZ: ACESSO E PERMANÊNCIA NO CONTEXTO DA CHAMADA “GUERRA ECONÔMICA" (2014-2018)
}

\author{
Francis Mary Guimarães Nogueira ${ }^{1}$ \\ Bruna da Silva Alves ${ }^{2}$
}

\section{RESUMO}

A morte de Chávez, em 2013, impactou na continuidade e manutenção do projeto societário bolivariano. Prenunciou-se, desde então, um novo contexto político-econômico, no qual o atual presidente Nicolás Maduro vem enfrentando ataques estratégicos do imperialismo estadunidense. Diante desse cenário, este artigo, de cunho bibliográfico e documental, pretende observar o impacto e os desdobramentos de algumas ações da chamada "guerra econômica" no acesso à educação básica da Venezuela. Para isso, na primeira seção, apresenta-se brevemente a trajetória histórica e legal de implementação e avanço do sistema educativo bolivariano, com recorte para o programa nacional denominado de Misiones Educativas Bolivarianas, que alavancou os índices de acesso à educação durante os governos Chávez. Em seguida, aborda-se, sumariamente, a conjuntura venezuelana no período pós-Chávez, com o intuito de entender como os aspectos qualitativos e quantitativos, referentes ao acesso e permanência na educação

\footnotetext{
${ }^{1}$ Pós-doutora em Educação pela Universidade Central da Venezuela (UCV, 2011), Doutora em Filosofia e História da Educação pela Universidade Estadual de Campinas (UNICAMP, 1998), Mestre em História e Filosofia da Educação pela Pontifícia Universidade Católica de São Paulo (PUC, 1993), graduada em Letras pela Universidade Tuiuti do Paraná (1987), membro do Grupo de Pesquisa em Política Social (GPPS/UNIOESTE); Professora Associada na Universidade Estadual do Oeste do Paraná (UNIOESTE), Campus de Cascavel, PR). ORCID: https://orcid.org/0000-0003-0778-4939. E-mail: francisg@terra.com.br.

2 Mestre em Educação (UNIOESTE, 2015), Pós-graduada em Psicopedagogia Clínica e Institucional (UCAM, 2018), graduada em Pedagogia (UNIOESTE, 2012), pós-graduanda em Neurociências e Educação Especial e Inclusiva (UCAM, 2021), integrante do Grupo de Pesquisa em Política Social (GPPS/UNIOESTE), pedagoga educacional na Universidade Federal de Santa Catarina (UFSC, Campus de Blumenau). ORCID: https://orcid.org/00000002-7065-7281. E-mail: bruna_alves2305@hotmail.com.
} 
básica, foram impactados a partir da penetração e interferência norte-americana na estrutura político-social e econômica venezuelana. Apesar de o governo de Nicolás Maduro ter buscado medidas de enfrentamento aos ataques norte-americanos para atenuar as consequências do embargo econômico, a educação básica já apresenta sinais de que tem sido afetada, vertiginosamente, em um curto período de tempo.

Palavras-chave: Educação básica. Acesso e permanência. "Guerra econômica" na Venezuela.

\section{ELEMENTARY EDUCATION IN VENEZUELA POST-CHAVEZ ERA: ACCESS AND STAY IN THE CONTEXT OF THE SO-CALLED "ECONOMIC WAR" (2014-2018)}

\section{ABSTRACT}

Chávez's death, in 2013, impacted on the continuity and maintenance of the Bolivarian society project. Since then, a new political-economic context was predicted, in which the current president Nicolás Maduro has been facing strategic attacks from the US imperialism. In the face of this scenario, this article, which is a bibliographic and documentary one, intends to observe the impact and the developments of some actions of the so-called "economic war" in the access to elementary education in Venezuela. In order to that, in the first section, we are going to briefly focus on the legal and historical trajectory of the implementation and the advance of the Bolivarian education system, with emphasis on the national program called Misiones Educativas Bolivarianas, which rose the rates of the access to education during Chávez's presidency. Next, we are going to approach, succinctly, the Venezuelan context in the post-Chávez era, with the objective of understanding how the qualitative and quantitative aspects, referring to the access and stay in elementary education, were impacted as of the North American entry and interference in the Venezuelan economic and social-political structure. Besides Nicolás Maduro's presidency searched for confrontation measures to the North American attacks to mitigate the consequences of the economic 
sanctions, the elementary education already presents signs that has been affected, vertiginously, in a short period of time.

Keywords: Elementary education. Access and stay. "Economic war" in Venezuela.

\section{EDUCACIÓN BÁSICA EN VENEZUELA DESPUÉS-CHAVÉZ: ACCESO Y PERMANENCIA EN EL CONTEXTO DE LA LLAMADA "GUERRA ECONÓMICA" (2014-2018)}

\section{RESUMEN}

La muerte de Chávez, en 2013, impactó la continuidad y el mantenimiento del proyecto corporativo bolivariano. Desde entonces, se ha anunciado un nuevo contexto político-económico, en el que el actual presidente Nicolás Maduro, ha estado enfrentando ataques estratégicos del imperialismo estadounidense. Por el escenario, este artículo, de naturaleza bibliográfica y documental, pretende observar el impacto y los desarrollos de algunas acciones de la llamada "guerra económica" en el acceso a la educación básica en Venezuela. Con esto propósito, en la primera sección, se presenta brevemente la trayectoria histórica y legal de la implementación y el avance del sistema educativo bolivariano, con un enfoque en el programa nacional llamado Misiones Educativas Bolivarianas, que tuvo apalancados los índices de acceso de la educación durante los gobiernos de Chávez. En seguida, se abordará brevemente la situación venezolana en el período posterior a Chávez, con objetivo de comprender cómo los aspectos cualitativos y cuantitativos, relacionados con el acceso y la permanencia en la educación básica, se vieron afectados por la penetración e interferencia norteamericana en la estructura político-social y económica venezolana. A pesar de que el gobierno de Nicolás Maduro buscó medidas para combatir los ataques norteamericanos para ablandar las consecuencias del embargo económico, la educación básica ya muestra signos de que ha sido afectada, dramáticamente, en un corto período de tiempo. 
Palabras clave: Educación básica. Acceso y permanencia. "Guerra económica" en Venezuela.

\section{INTRODUÇÃO}

Desde o ano de 2006, o Grupo de Pesquisa em Política Social (GPPS), da UNIOESTE, campus de Cascavel, PR, realiza estudos relacionados à América Latina e à temática venezuelana.

As pesquisas desenvolvidas sobre a Venezuela estiveram atreladas à conjuntura política e social do país, em específico à educação escolar básica e às mudanças jurídico-políticas na estruturação do sistema educativo. O caso da Venezuela tem despertado o interesse de estudos e análises desde que buscou novas formas de gestar suas políticas sociais na educação, presentes nos marcos legais da Constituição de 1999 e da Revolução Bolivariana. A implantação de programas educacionais específicos, como o Programa Misiones Educativas, acompanhou as novas diretrizes nacionais e as significativas transformações sociais. Documentos e indicadores qualitativos e quantitativos apontaram para o alavancamento dos índices de acesso e permanência estudantil, principalmente na educação básica.

Destaca-se, como um marco importante no campo educacional, o forte incremento financeiro advindo dos recursos do petróleo, que fizeram da Venezuela, já no ano de 2005, território livre de analfabetismo e um país mundialmente reconhecido como referência nas metas sociais e educacionais estabelecidas pela ONU.

A partir de 2013, a morte de Chávez porém, afeta a continuidade do projeto bolivariano. Emerge, pois, outro contexto de instabilidade, no qual a Venezuela perde sua principal liderança política e passa por um período de adaptação na transição ao novo governo. Nicolás Maduro, como propôs Chávez, seguiu firme com o projeto bolivariano. Mesmo sem a popularidade do ex-presidente, coube a Maduro enfrentar os condicionantes históricos, que se ensejaram no post mortem de Chávez, para tocar o projeto societário adiante, combatendo, com o apoio do parlamento chavista, a forte oposição político-econômica interna, praticada por grandes 
empresários e críticos de seu governo, além de sucessivos e recorrentes ataques à democracia e soberania venezuelana, pela chamada "guerra econômica" ${ }^{3}$ promovida pelo governo estadunidense.

Considerando-se este contexto, o presente artigo busca observar a incidência, a curto prazo, da chamada "guerra econômica" sobre os índices de acesso e permanência na educação escolar básica do país.

Para isso, a primeira seção traz um breve histórico da implementação da educação escolar bolivariana na Venezuela, baseado na legislação e na composição documental referentes à estrutura do sistema educativo. Ademais, são descritos alguns dados, indicadores de acesso e de permanência na educação básica e a importância da criação do programa Misiones Educativas para a ampliação da cobertura e culminação escolar.

Aborda-se, em seguida, um breve panorama da situação política e econômica do país sob o governo Maduro. Um momento conturbado para a sociedade venezuelana, que tem sido duramente atacada e solapada pelos desdobramentos da "guerra econômica". Destarte, são apresentadas algumas considerações sobre a situação da educação escolar básica na Venezuela nesse período; esboçados alguns dados qualitativos; e alguns percentuais recentes sobre 0 acesso e permanência estudantil.

Para compreender de forma menos rasa e, portanto, mais aprofundada tal caso, faz-se necessário ainda, o entendimento dos artifícios políticos e mecanismos econômicos do Capital. A funcionalidade do "ciclo" da globalização dos mercados, da macroeconomia, leva à compreensão do que significa uma "ofensiva" imperialista sobre a Venezuela, e como isso se reverbera nos substratos sociais, sobretudo no sistema educacional.

\footnotetext{
3 Darc Costa (2019) descreve que a guerra, em sua forma econômica, pode ser definida como aquela decorrente de uma agressão de natureza econômica. Segundo o autor, suas formas mais usuais são: as agressões financeiras, dirigidas a moedas, na forma de ataques especulativos que podem desestabilizar a economia de um país; ou as agressões comerciais, decorrentes da ação do poder econômico sobre a abertura ou fechamento de mercados ou, ainda, sobre o controle de fluxos de recursos. Assevera o autor que a guerra, no estilo econômica, tem sido usualmente praticada, desde o final do século XX e início do século XXI, sob o manto da "paz" e do discurso da "estabilidade".
} 
Trata-se, pois, segundo Mészáros (2011), de compreender, a partir do ciclo sóciometabólico do Capital, o quão declarada está a guerra econômica para qualquer país ou nação que ouse enfrentar as sanções e/ou imposições dos grandes blocos econômicos. Isto porque, com o esgotamento do modelo expansionista do capitalismo mundial, emerge novamente a tendência de conquista e domínio territorial, destacado por Mészáros (2011), como um processo de recolonização das Américas.

Há uma espécie de relançamento da velha prática imperial, por meio da qual o imperialismo, afetado pela crise estrutural do "liberalismo global", recorre à conquista e controle de territórios ricos em biodiversidade e em fontes de minerais, ambos estratégicos, incluindo grande contingente de força de trabalho (MARTINS, 2019).

Também é importante assinalar que, historicamente, desde a década de 1990, os países latino-americanos sofrem uma série de restrições que os forçam a seguir as recomendações de ajustes fiscais e orçamentários impostos pelos organismos internacionais. Essa prática tem se intensificado na última década, por meio do acirramento de sanções, bloqueios políticos e econômicos norteamericanos, mostrando uma face cada vez mais agressiva e enérgica do capital.

\section{A REESTRUTURAÇÃO DA EDUCAÇÃO ESCOLAR BÁSICA NOS GOVERNOS CHÁVEZ}

Inspirada nos ideais de Simón Bolívar - o Libertador -, a Revolução Bolivariana teve início com a chegada de Hugo Chávez à presidência da Venezuela, em 1999 (NOGUEIRA; RIZZOTTO, 2009). Naquela época, o governo Chávez propunha a necessidade de construção contínua e permanente de outra base política, econômica e cultural no país. Para coadunar com o estabelecimento de uma nova organização social, a educação formal foi replanejada estrategicamente.

Sucederam-se mudanças no campo educacional, concomitantes às transformações político-econômicas que se configuraram nos demais setores sociais. O ideário bolivariano previa 
que as instituições sociais recebessem maior aporte de incrementos financeiros para que fossem efetivadas as mudanças substanciais. Nesse intuito, além do aumento de recursos materiais, o sistema educacional passou também por uma reestruturação pedagógica e organizacional, de modo a corresponder à formação do novo cidadão venezuelano.

Para fomentar esse projeto, o governo bolivariano utilizou-se de dispositivos constitucionais e documentais, para assegurar, na letra da Lei, a educação escolar como direito de todos, e como prioridade e dever do poder público para com o crescimento e o fortalecimento do Estado. Com esse objetivo foram elaborados os seguintes documentos: (i) Escolas Bolivarianas: avanço qualitativo do projeto de 2004; (ii) Sistema Educativo Bolivariano (SEB), de 2007; (iii) Currículo Nacional Bolivariano (CNB), de 2007; e (iv) a Lei Orgânica de Educação (LOE), de 2009. Tais documentos orientaram a construção do novo sistema educativo, afirmando o período de profundas transformações vivido pelo país. Assinalaram, sobretudo, a relevância da educação no processo de refundação republicana, pois: " $L a$ educación, concebida como un proceso indisolublemente ligado a las fuerzas que impulsan el crecimiento cualitativo y el desarrollo del país, alcanza un valor estratégico de vital importancia" (VENEZUELA, 2007b, p. 2).

Perseguindo esse propósito, o sistema educacional do país acompanhou, de forma ideológica e estratégica, o movimento de transição em direção à construção do novo Estado socialista:

EI SEB requiere su consolidación, solicitada desde el
proceso de transición hacia el socialismo del siglo
XXI y que apuesta a la construcción de un diseño
curricular que dé respuestas y concretice los
procesos de enseñanza y aprendizaje acordes con
las necesidades e intereses de la nueva sociedad
revolucionaria (VENEZUELA, 2007b, p. 2).

Ratifica-se essa intencionalidade também no Currículo Nacional Bolivariano, que pretende em sua elaboração "[...] generar las transformaciones que Venezuela necesita y se convierta nuestro país en ejemplo para el mundo" (VENEZUELA, 2007a, p. 8). 
Para tanto, em colaboração com professores de todo o país, foi necessário ao Estado venezuelano elaborar um projeto educacional e implementar uma série de programas e políticas educacionais que correspondessem ao modelo político-social em andamento no país. Isso significa que as políticas públicas gestadas visaram assegurar

[...] la inclusión, permanencia, prosecución y culminación de los estudios en todos los niveles educativos; lo cual implica avanzar hacia una educación emancipadora, liberadora y dignificante, en el marco de los principios constitucionales (VENEZUELA, 2007a, p. 12).

Os avanços percebidos no contexto socioeconômico resultaram do movimento de reorganização da estrutura jurídicopolítica do país e da redefinição constitucional da concepção de Estado, que passou a orientar-se para a consolidação de um "[...] Estado democrático e social de direito e de justiça" (VENEZUELA, 1999, p. 1, grifo nosso). Nessa acepção, o Estado reconhece a dívida socio-histórica que tem para com a nação e a necessidade de garantir políticas sociais e educacionais inclusivas e massivas. Como também expresso na Carta Magna, a promoção da justiça social requer que, para além da igualdade de oportunidades, haja também meios e formas de possibilitar a igualdade de condições.

Com essa finalidade no campo educacional, o Estado bolivariano estruturou duas grandes estratégias para ampliar o acesso e a inclusão de todos os grupos sociais e étnicos. A primeira estratégia foi a de reestruturação do modelo de educação infantil, básica, média e universitária denominadas projetos: Simoncitos, Escuelas Bolivarianas, Liceos Bolivarianos, Escuelas Técnicas Robinsonianas, Educación Intercultural Bilingüe. A segunda estratégia foi a do desenvolvimento do Programa denominado de Misiones Educativas, composto pelas Misiones Robinson I e II, para alfabetização e escolarização primária; Misión Ribas, para escolarização secundária; e Misión Sucre, para a educação universitária. Este Programa foi uma alternativa para garantir o acesso e conclusão do processo de escolarização à toda a população, 
inclusive para as pessoas que estavam fora da idade escolar e socialmente marginalizadas.

Com a implantação da Educação Bolivariana e do Sistema Nacional Inclusivo das Missões, Nogueira e Rizzotto (2009) destacam que:

[...] o governo Chávez iniciou um processo de criação de condições infraestruturais em todos os setores da economia e também nos setores sociais. No setor da educação escolar, instituiu o Sistema de Educação Bolivariano, que deverá susbstituir o sistema regular ainda em vigência gradativamente, associado às missões educativas, programas experimentais que visam a incluir os excluídos do sistema escolar tradicional, em todos os níveis de ensino (NOGUEIRA; RIZOTTO, 2009, p. 110).

Ressalte-se ainda que:

As missões educativas apresentam-se como estratégias de educação que combatem a exclusão das pessoas alijadas historicamente dos diversos níveis de escolaridades por falta de condições de acesso, resultado da precária distribuição de renda e da concentração, nas mãos de poucos, da renda petroleira (NOGUEIRA; RIZZOTTO, 2009, p. 111).

Com o novo sistema educativo bolivariano e as estratégias paralelas de acesso, houve notadamente um processo massivo de universalização da educação escolar. Percentuais do Instituto Nacional venezuelano de Estatística (INE) demonstraram que, o número de alunos em idade escolar matriculados na educação básica inicial (que atende crianças de 0 a 6 anos nos centros educacionais denominados Simoncitos), que era de 46,4\% em 2001, aumentou para $71,4 \%$ no ano de 2011 , e o índice de estudantes que acessaram as Escuelas Bolivarianas (correspondente ao Ensino Fundamental no Brasil, e que atende crianças de 7 a 12 anos) atingiu 93,2\% de cobertura. Nesse mesmo ano de 2011, o número de matrículas nos Liceos Bolivarianos (Ensino Médio, ofertado aos adolescentes e jovens 
entre 13 e 18 anos) atingiu 73,3\% dos alunos em idade escolar correspondente.

Estes indicadores percentuais revelaram um aumento considerável do alcance das políticas educacionais na Venezuela. Este processo, apontado por Flores (2010), pode ser compreendido como um modelo revolucionário de gestar e implementar políticas públicas. Frisa o autor que: "Las misiones representan el mayor esfuerzo público que haya conocido la nación para enfrentar corresponsablemente las necesidades del pueblo venezolano" (FLORES, 2010, p. 4).

Depreendendo-se que as mudanças sociais no país levaram à necessidade histórica de reconfiguração legal do sistema educativo, em 2009 foi sancionada a Lei Orgânica de Educação (LOE), que estabeleceu as diretrizes da educação nacional de acordo com os ideais bolivarianos; dentre elas, a educação como direito indeclinável e de máximo interesse do Estado.

A LOE (2009) ratificou a educação como um direito humano e também um dever social, voltada para o desenvolvimento do potencial de cada ser humano e centrada na criação, transmissão e apreciação das diversas manifestações e valores culturais para a transformação da realidade (VENEZUELA, 2009).

Como proposto na legislação, coube à instituição estatal assegurar e prover meios que permitissem, a cada indivíduo no país, acessar a educação com igualdade de condições e oportunidades, contribuindo, assim, com a extinção da educação dual e excludente que gera desigualdade social. Esses aspectos sugerem uma nova atuação do Estado, para além dos marcos legais, e que de fato "[...] se comprometa a cumplir con su papel de creador de las condiciones para que sea realidad una educación de calidad para todos" (VENEZUELA, 2004, p. 13).

Um aspecto importante para o acesso e a permanência escolar foi o direcionamento estatal, que, mediante dispositivo constitucional, determinou que todos os cidadãos tivessem direito a uma educação plena, integral, permanente, contínua e de qualidade, estabelecendo uma política de gratuidade absoluta nas instituições educacionais públicas, até para a educação universitária (VENEZUELA, 2009, grifo nosso). Essa política pontual teve como objetivo garantir, 
não somente a inclusão, mas, também, a permanência dos estudantes no sistema educacional.

Outra medida estratégica de permanência e qualidade educativa, durante os governos Chávez, foi a implantação da escola bolivariana, com jornada escolar em tempo integral e proposta pedagógica específica. Além da incorporação de novas tecnologias de informação e comunicação ao processo educativo, visando à formação crítica e reflexiva dos estudantes, o poder público assumiu, ainda, o dever de zelar pela qualidade da infra-estrutura das instituições oficiais de ensino e pela construção de novas unidades escolares para aumentar o tempo de permanência dos sujeitos nas instituições educacionais.

Acerca desses aspectos é importante considerar a intenção de que:

[...] os venezuelanos estejam na escola por tempo cada vez mais prolongado da sua vida: a Constituição de 1961 impunha a escolaridade obrigatória de 6 anos, no mínimo; a Lei Orgânica de 1980 estabelecia para 9 anos; o regulamento dessa lei, em 1986, aumenta um ano de escolaridade no pré-escolar; a Constituição de 1999 amplia a obrigatoriedade dos indivíduos e do Estado para 17 ou 18 anos [...] (NOGUEIRA; ZUCK; 2008, p. 3).

A Lei Orgânica de Educação de 2009 estabeleceu, como principal, a obrigatoriedade da educação formal em consonância com o ideário do libertador Simón Bolívar, a fim de manter "vivas" a história e a luta pela independência dos países latino-americanos. A proposta pedagógica incluiu, para tanto, a prática de esportes, artes, recreação, saúde, hábitos alimentares, agroecologia, comunicação, além da incorporação de projetos e programas institucionais de apoio.

Segundo a avaliação governamental, o projeto educacional bolivariano indicou a possibilidade de superação de discursos retóricos educativos, ao firmar o compromisso legal com uma prática pedagógica aberta, reflexiva e construtiva, que tende a impulsionar uma mudança efetiva do sistema escolar, de suas concepções pedagógicas e procedimentos metodológicos. Dessa forma, a escola 
bolivariana remete e corresponde à identidade e ao momento histórico revolucionário vivido pela nação venezuelana (VENEZUELA, 2004).

Nessa direção, para combater os fatores causais da desigualdade socioeconômica que levam à exclusão educacional, o Estado ampliou o alcance de políticas de proteção social à população mais vulnerável. Políticas sociais que se materializaram através do auxílio para transporte, alimentação, assistência médica, uniformes, roupas, calçados, bem como orientação pedagógica e vocacional, com a finalidade de melhorar a igualdade de condições oferecidas aos estudantes (VENEZUELA, 2004).

Conforme Rodríguez Trujillo (2008), o Estado busca atender às necessidades educacionais de todos os cidadãos venezuelanos negligenciados e marginalizados historicamente, o que caracteriza a escola como uma instituição pertencente e conduzida pela comunidade.

Nessa direção, é importante enfatizar que:

As políticas educacionais desenvolvidas nesse período acenam para uma nova forma de governar, baseada na distribuição equânime dos recursos públicos, tratando de forma diferente os diferentes. Esta parece ser a alternativa encontrada pela Venezuela para a construção de uma nova sociedade e, consequentemente, de uma história educacional diferenciada para o seu povo, pois aqueles que historicamente foram esquecidos e abandonados pelo Estado careciam de políticas sociais e educacionais que garantissem a distribuição da riqueza e a igualdade social (ALVES; NOGUEIRA, 2013, p. 13-14).

Definiu-se, sobretudo no Currículo Nacional Bolivariano, que a educação deve ser instituída junto e com o país, em um processo histórico e social abrangente, integral e permanente, respaldada pela Constituição venezuelana (VENEZUELA, 2007a).

Expressa, ainda, o currículo que:

La Educación Bolivariana se define como un proceso político y socializador que se genera de las 
relaciones entre escuela, familia y comunidad; la interculturalidad, la práctica del trabajo liberador y el contexto histórico-social (VENEZUELA, 2007a, p. 15 , grifo do autor).

Demostra-se, dessa forma, que a proposta de qualidade educacional venezuelana requer que a educação escolar possibilite o domínio dos conhecimentos históricos construídos nos diversos contextos socioculturais, para que se compreendam: o caráter social contido no conhecimento, a sua utilização no cotidiano, e as condições necessárias para que se reconheçam e se analisem os variados problemas sociais, políticos e ambientais.

Nessa direção, o sistema educativo bolivariano parece apresentar-se como um modelo educacional genuíno e contemporâneo, pois, ao passo que visa promover o atendimento, conscientização e valorização da diversidade multiétnica, intercultural, pluricultural, visa às necessidades educacionais especiais de seu povo.

A educação escolar básica bolivariana: alguns aspectos da chamada "guerra econômica" no recente caso venezuelano

Desde a morte do presidente Hugo Chávez, na Venezuela, em março de 2013, Nicolás Maduro tem lutado para manter a estabilidade de seu governo frente ao forte e agudo intervencionismo estadunidense. Frequentemente, a Venezuela tem sido alvo de ataques midiáticos internacionais e assunto nas reuniões do Conselho de Segurança das Nações Unidas.

Desde 2014, a Casa Branca, sob o aval do, à época, presidente Barack Obama, vem coordenando uma série de sanções políticas e econômicas que visam desestabilizar a economia venezuelana para, consequentemente, atingir o governo e a liderança política de Maduro.

Além do congelamento de bens e restrições de vistos às autoridades venezuelanas, o governo de Donald Trump colocou em prática uma política macroeconômica agressiva e cirúrgica, seguida, sobretudo, pelo Canadá e União Europeia, o que rapidamente levou 
ao colapso da economia venezuelana, totalmente dependente da petrolífera PDVSA 4 .

Trump proibiu americanos de negociarem títulos públicos venezuelanos e empréstimos bancários à Venezuela e à PDVSA. Estima-se que o impacto de tais medidas tenha congelado 30 bilhões de dólares pertencentes ao país e que tenha retido na Citgo, filial da PDVSA nos EUA, um montante de 15 bilhões de dólares também pertencentes à Venezuela (BARROCAL, 2019).

Ocorre que tais sanções, além de solaparem a situação política e econômica da Venezuela, têm gerado uma crescente crise política internacional entre as potências mundiais. Isso porque importantes parceiros comerciais, como Rússia e China, têm sofrido esse impacto bilionário em suas próprias economias pelas restrições norteamericanas; ou seja, o chamado "efeito dominó".

Destaca Mantovani (2017) que, além do intervencionismo estadunidense, as parcerias entre Venezuela e China têm favorecido também a interferência deste país, nas políticas e medidas econômicas venezuelanas. Esta aliança tem afetado a soberania nacional, uma vez que aumenta sua dependência desta potência asiática e promove abertura para processos de flexibilização econômica, gerando acumulação capitalista transnacional e apropriação de recursos naturais venezuelanos.

Esta conjuntura político-econômica da Venezuela, no cenário mundial, levou a uma espécie de "Guerra Econômica", tanto externa, com os bloqueios e sanções ordenadas por Washington, como interna, pela forte oposição política ao governo Maduro, representada pela figura do autoproclamado presidente Juan Gerardo Guaidó Márquez.

A correlação de forças contrárias e arbitrárias orquestradas contra a Venezuela desmoronou principalmente seus setores sociais, atingindo a população em geral. Na educação, os desdobramentos negativos do atual contexto venezuelano já são perceptíveis. Os avanços alcançados pela Revolução Bolivariana, nos governos Chávez, apontavam para conquistas educacionais importantes, principalmente quanto ao acesso e permanência estudantil na

\footnotetext{
4 Petróleos de Venezuela S. A.
} 
educação básica e na ampliação e gratuidade inclusive para a educação universitária.

Em 2011, o caderno governamental Logros y Avances del Gobierno Bolivariano apresentou dados quantitativos relevantes em relação à gestão do governo bolivariano. No concernente à educação, destacou-se o aumento das taxas brutas de matrículas na educação básica e universitária.

Conforme descrito no documento supracitado, a Venezuela, em 2011, era o país com a menor desigualdade social da América Latina e o segundo em matrículas universitárias, atrás apenas de Cuba; em 1998, havia 785 mil estudantes universitários, enquanto no censo de 2011, foram constatados mais de 2 milhões e 300 mil, o que significou um aumento de mais de $300 \%$ nas matrículas. De acordo com dados da UNESCO, a Venezuela foi considerada, nessa época, o $2^{\circ}$ país da América Latina, e o $5^{\circ}$ do mundo, com maior índice de matrículas universitárias.

Na educação básica inicial, o número de alunos atendidos também se elevou significativamente em relação ao ano de 1998 , período em que havia pouco mais de 700 mil matrículas. De acordo com dados coletados em 2011, foram mais de 2 milhões e 200 mil crianças regularmente matriculadas (VENEZUELA, 2012).

Conforme a tabela 1, abaixo, os índices de um levantamento realizado em 2012 revelaram o avanço da universalização da educação na Venezuela:

Tabela 1 -Taxa bruta de escolaridade por nível de ensino do subsistema de educação básica da República Bolivariana da Venezuela.

\begin{tabular}{l|c|c|c}
\hline Nível de ensino $^{5}$ & $\mathbf{1 9 9 2 - 1 9 9 3}$ & $\mathbf{1 9 9 9 - 2 0 0 0}$ & $\mathbf{2 0 1 1 - 2 0 1 2}$ \\
\hline Inicial & $43 \%$ & $46 \%$ & $70,5 \%$ \\
Primária & $89 \%$ & $88 \%$ & $92,2 \%$ \\
Média & $47 \%$ & $51 \%$ & $75,1 \%$ \\
\hline
\end{tabular}

Fonte: Tabela elaborada com base nos registros administrativos de estatísticas do Ministério do Poder Popular para a Educação (MPPE), publicados no caderno Consulta Nacional por Calidad Educativa - resultados. (VENEZUELA, 2014).

${ }^{5}$ Conforme estabelecido na Lei Orgânica de Educação de 2009 
No entanto, desde 2014, a economia venezuelana vem sendo asfixiada por ações político-econômicas pontuais. O governo norteamericano, em um de seus comunicados sobre o país, afirmou que as sanções foram "calibradas estrategicamente" de modo a paralisar o projeto político-ideológico em curso na Venezuela (BARROCAL, 2019).

A execução dessas sanções de ordem econômica e diplomática leva a uma rápida resposta do mercado mundial e, consequentemente, ao colapso do Estado venezuelano, que tem como sua principal base econômica o extrativismo do petróleo.

As imbricações da atual "guerra econômica" têm golpeado, sobretudo, o sistema educacional bolivariano. Das aproximadamente 8 milhões de crianças matriculadas na educação básica, estima-se que apenas 3 milhões delas estejam conseguindo, atualmente, acessar a escola, devido à conjuntura no referido país (MORAIS, 2018). Esta estimativa, se comparada à do ano de 2012, quando havia uma taxa média de matrículas na educação básica (inicial, primária e média) em torno de $79,26 \%$, revela a ocorrência de um rápido despencamento dos índices; isto porque a média de acesso à educação básica, em 2018 , ficou na margem de $37,5 \%$, o que corresponde a uma queda de $41,76 \%$ na cobertura. Esses dados sinalizam para uma situação alarmante devido ao fato de que, sem estabilidade nas relações e condições econômicas, não há como manter a continuidade e os avanços do projeto educacional em curso. Evidencia-se, nesse contexto, um período de retrocesso na universalização do acesso à educação escolar, mesmo com o estabelecimento de uma política incisiva do governo bolivariano, que destinou $75 \%$ do orçamento nacional aos setores sociais.

Relata Mantovani (2017) que a quebra na economia levou ao colapso do sistema de transportes, ao aumento exorbitante das tarifas de ônibus e a frequentes cortes de água e luz nas instituições escolares. Além de que, a escassez de alimentos e a dificuldade no transporte gerou o desabastecimento de produtos da merenda escolar. O autor ressalta, ainda, a dificuldade na produção e distribuição de alimentos na Venezuela, o que vem gerando uma hiper-concentração populacional nas cidades (cerca de 90\%) e 
obrigando a importação de produtos de necessidade básica, com a consequente logística de armazenamento e abastecimento eficientes.

O "caos" econômico ocasionou a desestabilização do governo Maduro, principalmente pelo alto índice inflacionário no país e devido ao processo de reconversão monetária, que desvalorizou imensamente a moeda venezuelana, com as práticas de "câmbio clandestino" e de venda do "DólarToday"6 no mercado paralelo.

Estima-se que os preços das mercadorias subiram mais de $8.000 \%$ em apenas 12 meses. Essa situação sufocante provocou, no setor educacional, uma verdadeira diáspora de profissionais docentes. Sem condições de se manterem economicamente e de continuarem lecionando, centenas de professores têm deixado o país. Há indícios de que $45 \%$ dos docentes da rede pública de ensino e $60 \%$ da rede privada tenham abandonado suas aulas Os professores pertencem ao grande contingente de venezuelanos que têm emigrado do país (RODRíGUEZ, 2018). Desde 2015, cerca de 3,4 milhões de cidadãos deixaram a Venezuela em decorrência do boicote dos bancos e da dificuldade de obtenção de comida e remédios. Configura-se, tal situação, também como um desdobramento da "guerra econômica" interna, praticada pela oposição política ao governo Maduro. A maior parte da economia ainda concentra-se no setor privado, que inúmeras vezes tem sido denunciado por fomentar casos de estocagem e açambarcamento ${ }^{7}$ de mercadorias de necessidade básica (BARROCAL, 2019).

${ }^{6} \mathrm{O}$ "DólarToday" é um site americano destinado a política e finanças latino-americanas. Essa empresa ficou bastante conhecida por ser uma "referência" cambial internacional do "Bolívar Soberano" (moeda venezuelana atual e não livremente conversível). Ocorre que, com a flutuação da economia na Venezuela e o alto índice inflacionário, o site tem ofertado uma cotação diária específica, e cada vez mais baixa, do Bolívar Soberano, o que tem sido utilizado como referência para mensurar o valor atribuído à moeda no "mercado paralelo", elevando a especulação e a desvalorização do dinheiro venezuelano. Essa prática econômica, considerada ilegal de acordo com a legislação do país, com uma cotação diferenciada em relação ao livre mercado para a Venezuela, tem alimentado o mercado clandestino e provocado taxas alarmantes de inflação (SULBARÁN, 2016).

${ }^{7}$ Trata-se de termo da economia industrial para descrever a ação praticada por monopólios que dominam certo setor produtivo ou comercial da economia, consiste na retenção/estocagem de matérias-primas, bens de capital ou gêneros de primeira necessidade com o intuito de elevar preços, eliminar concorrentes ou dominar o mercado, o que é considerado crime pela legislação de diversos países (COMIN, A. Glossário de termos de economia industrial, Versão 3. PUC-SP, portal eletrônico. 
Além da retenção de mercadorias, ocorrem indícios de alimentos e medicamentos armazenados, que quando liberados, não estão sendo destinados ao abastecimento de supermercados e farmácias, mas, sim, ao comércio ilegal, com preços altamente inflacionados no "mercado paralelo" (BARROCAL, 2019).

Analisa Mantovani (2017) que a atual conjuntura venezuelana também resulta de um cenário caótico e corrompido, além de uma profunda crise institucional. $\mathrm{O}$ autor assinala:

La crisis histórica del modelo de acumulación rentista petrolero, la metástasis de la corrupción en el país, severas vulneraciones al tejido social desde el "período neoliberal" y en especial desde 2013, y la intensidad de los ataques y disputas políticas, han desbordado en su conjunto los marcos de las instituciones formales de todos los ámbitos de la sociedad, canalizándose muy buena parte de las dinámicas sociales por la vía de mecanismos informales, subterráneos e ilegales (MANTOVANI, 2017).

A atual situação vivenciada pela Venezuela, de crise institucional, política e econômica, resulta da execução de um projeto imperialista, emergencial, de "ataque" às novas sociedades emergentes da América Latina; no caso venezuelano, de "frear" a continuidade de um determinado projeto societário, que poderia, a longo prazo, comprometer a posição de potência mundial que os EUA têm ocupado. Destaca Magdoff apud Mészáros (2011) que:

[...] a característica essencial no novo imperialismo que surge no final do século XIX: é a luta competitiva entre as nações industriais para conquistar posições dominantes com relação ao mercado mundial e às fontes de matérias-primas. (MAGDOFF, 2011, apud MÉSZÁROS, 2011, p. 96).

Mészáros (2011, p. 96) ainda salienta que a humanidade chegou a uma fase potencialmente "fatal", denominada de

Disponível em https://www.pucsp.br/ acomin/economes/glosglob.html. Acesso em: 22 mar. 2019). 
"imperialismo global hegemônico", numa espécie de esgotamento e limitação estrutural do sistema.

A possibilidade de avanço do projeto bolivariano, que no atual momento representa a ascensão da esquerda sul-americana, a integração dos países do Cone $\mathrm{Sul}^{8}$ e as alianças comerciais com China e Rússia, contrastam diretamente com a pretensão dos Estados Unidos de se converterem na maior potência industrial petroleira. Desse objetivo decorre o cerco financeiro à Venezuela, a desestabilização do governo Maduro e o desmonte da PDVSA (MARTINS, 2019).

\section{CONSIDERAÇÕES FINAIS}

O caso da Venezuela aponta para uma condição histórica, única e singular na América Latina. Por seu significado geopolítico no contexto mundial, o país vem sofrendo, principalmente a partir da morte de Hugo Chávez, em 2013, medidas políticas arbitrárias e repressões econômicas violentas, por parte do governo estadunidense.

Nessa conjuntura, as conquistas históricas e sociais obtidas durante a chamada "Revolução Bolivariana" foram suprimidas em um curto período temporal. O setor educacional já apresentou um acentuado declínio em relação aos seus índices percentuais de acesso e permanência, em todos os níveis educacionais. Em específico, a educação básica sofreu uma espécie de "despencamento" dos índices de acesso escolar, devido aos fatores sociais e econômicos que incidiram diretamente na manutenção e fruição do sistema educacional. A diáspora docente, os cortes de energia, o encarecimento das passagens dos transportes, a falta de merenda escolar, a insegurança e violência urbanas formaram um verdadeiro contexto de "guerra", no qual se tornou inviável a frequência e permanência escolar.

\footnotetext{
${ }^{8}$ Região geopolítica composta por Argentina, Chile, Uruguai, Bolívia, Região Sul do Brasil, Peru e esporadicamente pelo Paraguai. Esses países formam uma macrorregião próspera e de economia emergente da América Latina, com alta expectativa de vida, alto Índice de Desenvolvimento Humano (IDH) e de padrão de vida, além de importante participação comercial nos mercados globais.
} 
Ressalte-se, também, a dispersão populacional e docente como fator agravante, pois o país está perdendo grande parte de sua "mão-de-obra" qualificada, além de muitos estudantes que cursam o último período da graduação, por ficarem sem aulas e sem perspectivas de obterem sua titulação profissional.

A crise econômica, implantada por interesses geográficos e políticos, tem abalado, acima de tudo, as alternativas de enfrentamento ao contexto atual. Sem poder e estabilidade econômica, devido às sanções e bloqueios estadunidenses, com o desgaste midiático internacional, a crescente emigração dos venezuelanos, a falta de alimentos e medicamentos causando calamidade pública e insegurança nacional, a Venezuela tem um grande desafio pela frente.

É importante observar que, apesar de existirem atualmente outros países, como México e Colômbia, com baixo IDH e percentuais estatísticos alarmantes de desigualdade social e econômica, muito próximos, inclusive, ao caso venezuelano, não há interesse da Casa Branca em interferir nas políticas de governabilidade destes países e de acabar com o que chamam de "crise humanitária" (MANTOVANI, 2017). Isso alerta para o fato de que há uma preferência intervencionista sobre a Venezuela, por seu potencial de extração do petróleo e, sobretudo, pelo projeto político-econômico e social que o país representa.

Os recursos naturais do país, sua localização geoestratégica (encurtaria o caminho do petróleo ao território estadunidense), seu enfrentamento às políticas do Consenso de Washington, revelam o potencial político e econômico desta pequena nação latinoamericana. Inclusive a sua peculiar história, a influência integracionista entre os países latinos e suas alianças comerciais com grandes blocos econômicos de forte poder bélico, como China, Rússia e Irã (MANTOVANI, 2017).

Essa condição singular da Venezuela coloca em "xeque" interesses mundiais, principalmente quanto à manutenção ou nova definição dos grandes blocos hegemônicos. Pois, as parcerias políticas e comerciais que possam se delinear, no atual contexto, podem ser determinantes para a emergência de um novo mapa da política macroeconômica. 
Os "olhos" do mundo se voltam para esse país sul-americano, que embora pareça insignificante diante de grandes nações que integram a economia global, pode ser estratégico para desmoronar o imperialismo norte-americano e estremecer as relações políticoeconômicas de potências mundiais. Dos desdobramentos do caso venezuelano, dependem os rumos da nova organização políticoeconômica mundial.

\section{REFERÊNCIAS}

ALVES, B. S.; NOGUEIRA, F. M. G. O acesso à educação escolar no subsistema de educação básica na Venezuela: História das políticas educativas nos governos Chávez (2003-2011). In: Seminário de Pesquisa do Programa de Pós-Graduação em Educação (PPE), 12. 2013, Maringá. Anais eletrônicos [...] Maringá: UEM, 2008 p. 1-17. Disponível em: http://www.ppe.uem.br/publicacoes/seminario_ppe_2013/trabalhos/ co_01/02.pdf. Acesso em: 20 mar. 2019.

BARROCAL, A. Guerra econômica dos EUA e da oposição "asfixia" a Venezuela. Carta Capital, 28 fev. 2019. Disponível em: https://www.cartacapital.com.br/mundo/guerra-economica-doseua-e-da-oposicao-asfixia-a-venezuela/. Acesso em: 22 mar. 2019.

COSTA, D. Os novos tipos de guerra. Cad. Est. Estratégicos, periódico do Centro de Geopolítica e Estudos Estratégicos da Escola Superior de Guerra (ESG), Rio de Janeiro, n. 1, 2019. Disponível em: https://www.esg.br/publi/arquivoscadernos/EdiodeMarode2019V2.pdf. Acesso em: 10 dez. 2019. FLORES, R. C. El Estado empotrado: las Misiones Bolivarianas como instrumentos de reforma de Estado. In: FLORES, R. C.; PÉREZ, A. M. et al. Capitalismo y revolución bolivariana en Venezuela. Venezuela: Producciones Editoriales, 2010. p. 15-103.

MANTOVANI, E. T. Venezuela: siete claves para entender la crisis actual. Sinpermiso: revista eletrônica semanal vinculada a revista semestral impressa com o mesmo nome. 28 maio 2017. Disponível 
em: https://www.sinpermiso.info/textos/venezuela-siete-claves-paraentender-la-crisis-actual. Acesso em: 28 mar. 2019.

MARTINS, C. E. Trump e a Venezuela. Blog da Boitempo, São Paulo, 20 fev. 2019. Disponível em:

https://blogdaboitempo.com.br/2019/02/20/trump-e-a-venezuela/. Acesso em: 28 mar. 2019.

MÉSZÁROS, I. O desafio e o fardo do tempo histórico: $O$ socialismo no século XXI. Tradução: Ana Cotrim, Vera Cotrim. 1. ed. revista. São Paulo: Boitempo, 2011.

MORAIS, T. Quase 3 milhões de crianças sem escola na Venezuela. 26 abr. 2018. RENOVA Mídia, portal eletrônico de conteúdo 2018. Disponível em: https://renovamidia.com.br/quase-3-milhoes-decriancas-sem-escola-na-venezuela/. Acesso em: 26 mar. 2019.

NOGUEIRA, F. M. G.; RIZZOTTO, M. L. F. Democratização da educação escolar: as Missões Robinson, Ribas e Sucre e o Estado venezuelano inscrito na Constituição de 1999. In: BORGES, L. F. P.; MAZZUCO, N. G. (Orgs.). Democracia e políticas sociais na América Latina. São Paulo: Xamã, 2009. p. 105-120.

NOGUEIRA, F. M. G.; ZUCK, D. V. A concepção de educação escolar bolivariana da Venezuela (de 2003-2008): Proyecto Simoncito,

Escuela Bolivariana e Liceo Bolivariano. In: SIMPÓSIO NACIONAL DE EDUCAÇÃO, 1 e SEMANA DE PEDAGOGIA, 20, 2008, Cascavel, Anais [...] Cascavel: Unioeste, 2008 p. 1-15.

RODRÍGUEZ TRUJILLO, N. Trayectoria del Proyecto de Escuelas Bolivarianas. Educere: revista venezuelana de educação da Universidad de los Andes, Mérida, Venezuela, seção: Investigación Arbitrada, v. 12, n. 42, p. 563/574, jul./sept. 2008. Disponível em: https://www.redalyc.org/pdf/356/35614569017.pdf. Acesso em: 28 mar. 2019.

RODRÍGUEZ, M. Crisis desploma sistema educativo. Diáspora masiva deja aulas sin profesores y sin estudiantes. ANSA Latina, Caracas, Venezuela, mar. 2018. Disponível em: http://www.ansalatina.com/americalatina/noticia/venezuela/2018/03 
/19/crisis-desploma-sistema-educativo_ad13001b-b865-4fff-9f430323e795464c.html. Acesso em: 20 mar. 2019.

SULBARÁN, P. Quiénes están detrás de Dólar Today, el sitio web al que Nicolás Maduro acusa de hacer la guerra económica a Venezuela. BBC Mundo, 7 mar. 2016. Disponível em:

https://www.bbc.com/mundo/noticias/2016/03/160224_dolar_today _quienes_son_venezuela_ps. Acesso em: 22 mar. 2019.

VENEZUELA. Constitución de la República Bolivariana de

Venezuela. Gaceta Oficial del jueves 30 de diciembre de 1999, n 36.860 .

VENEZUELA. Ley Orgánica (2009). Ley Orgánica de Educación. Gaceta Oficial Extraordinario de 15 de agosto de 2009, n 5.929.

VENEZUELA. Ministerio de Educación y Deportes. Escuelas Bolivarianas: avance cualitativo del proyecto. Caracas, 2004.

VENEZUELA. Ministerio del Poder Popular para la Comunicación y la Información (MippCl). Logros y avances del Gobierno Bolivariano

- 2011. Caracas, Venezuela: MippCl, 2012.

VENEZUELA. Ministerio del Poder Popular para la Educación. Consulta nacional por la calidad educativa: resultados. Caracas: MPPE, 2014.

Disponível em:

http://www.cerpe.org.ve/tl_files/Cerpe/contenido/documentos/Calidad \%20Educativa/PRESENTAClu00D3N\%20DEFINITIVA\%20DE\%20LA\%20C ONSULTA\%20POR\%20LA\%20CALIDAD\%20EDUCATIVA.pdf. Acesso em: 7 nov. 2014.

VENEZUELA. Ministerio del Poder Popular para la Educación.

Currículo Nacional Bolivariano. Diseño curricular del Sistema Educativo Bolivariano. Caracas: CENAMEC, 2007a.

VENEZUELA. Ministerio del Poder Popular para la Educación. Sistema Educativo Bolivariano. Caracas: CENAMEC, 2007b.

Submetido em: Julho/ 2020.

Aceito em: Fevereiro/ 2021. 